\title{
EDUCAÇÃO AMBIENTAL A PARTIR DA INTERAÇÃO ENTRE A SALA DE AULA E ARREDORES DA COMUNIDADE
}

Joádson Rodrigues da Silva Freitas ${ }^{1}$

André Scarambone Zaú ${ }^{2}$

Resumo: Avaliamos efeitos de atividades didáticas na percepção e cognição de questões ambientais, por parte de estudantes do ensino médio técnico no Instituto Federal de Educação, Ciência e Tecnologia do Amapá. Durante o segundo semestre de 2013 foram realizadas atividades práticas em sala de aula e ambientes externos, considerando diferentes temas ambientais. Análises quantitativas e observações qualitativas corroboraram a hipótese de que atividades de Educação ambiental contextualizadas e incluídas na rotina de aulas conduzem à maior percepção e compreensão a respeito de questões ambientais gerais e de problemas que os estudantes vivenciam em sua localidade.

Palavras-chave: Transversalidade; Práxis na Educação Ambiental; Observações Pedagógicas nos Arredores da Comunidade.

${ }^{1}$ Instituto Federal do Amapá. E-mail: joadson.freitas@ifap.edu.br

${ }^{2}$ Universidade Federal do Estado do Rio de Janeiro. E-mail: andrezau@unirio.br 


\section{Introdução}

Um dos desafios da escola é promover o desenvolvimento de uma compreensão integrada do meio ambiente em suas múltiplas e complexas relações, envolvendo aspectos ecológicos, psicológicos e legais, conforme preconizam os objetivos fundamentais da Educação ambiental (BRASIL, 1997). Formar cidadãos conscientes e atuantes numa sociedade complexa - sujeita a mudanças cada vez mais rápidas - demanda uma formação crítica, considerando condições históricas e atuais, mas também preparada para o novo, para o desconhecido, visto que, segundo Freire (1979), quando o homem compreende sua realidade, pode levantar hipóteses sobre o desafio dessa realidade e procurar soluções.

Problemas ambientais cada vez mais intensos, dificuldades que estudantes apresentam em abordagens da relação do homem com a natureza e obstáculos que professores enfrentam para trabalhar aspectos da Educação ambiental na escola fazem com que essa temática apresente grande relevância na atualidade. Apesar da concepção dominante que a Educação ambiental deva apresentar caráter transversal (BRASIL, 1988), a especialidade de cada docente, particularmente no ensino técnico, faz com que questões ambientais sejam tratadas de maneira eventual e de forma superficial. Por vezes, a escola planeja e até desenvolve ações de Educação ambiental, porém, via de regra, tais ações são pautadas apenas em datas comemorativas e/ou restritas aos temas do âmbito dos componentes curriculares de Ciências, Biologia e disciplinas afins. Esse tipo de ação, quando muito, proporciona ao estudante um conhecimento fragmentado e desconexo da realidade.

Diante dessa problemática, nossa pesquisa buscou respostas para questão do que poderia ser realizado pela escola para melhorar a cognição de estudantes sobre importantes questões ambientais do mundo atual. Nossa hipótese está baseada na concepção de que atividades sistemáticas e integradas de Educação ambiental favorecem de forma significativa a cognição de questões e problemas ambientais. A pesquisa partiu do pressuposto que estudantes adquirem uma compreensão mais ampla dos problemas ambientais a partir da vivência com ações que questionam paradigmas atuais, relacionados à forma de produção de bens provenientes de recursos naturais; que ponderam sobre o estímulo acrítico que nossa sociedade promove sobre o consumo e o consumismo; e que marginalizam o descarte ou o maquiam, apresentando como possível solução final a reciclagem (LEONARD, 2007).

A temática ambiental foi abordada com base nos temas "Educação ambiental formal" e "Educação ambiental no processo de Gestão ambiental", com ênfase na importância da utilização racional da água, no gerenciamento dos resíduos sólidos e em efeitos do processo de urbanização (BRASIL, 1997). Esta pesquisa teve como objetivo avaliar o efeito de atividades pedagógicas relacionadas ao cotidiano, na percepção e cognição sobre questões ambientais de estudantes do ensino médio técnico de um instituto federal de ensino. 


\section{Referencial teórico}

O termo Educação refere-se à comunicação e ao aprendizado das técnicas culturais, que são as técnicas de uso, produção e comportamento, mediante as quais um grupo é capaz de satisfazer suas necessidades (ABBAGNANO, 2003). O mesmo autor afirma que para a sociedade primitiva a Educação visava basicamente garantir a imutabilidade das técnicas de trabalho e de comportamento existentes na época. No entanto, ele observa que a Educação na sociedade contemporânea possui função não só de transmiti-las, mas também de aperfeiçoá-las e corrigi-las. O homem é um ser inacabado e, por isso, procura se educar de forma contínua (FREIRE, 1979). O autor aponta que a busca pela a educação deve ser realizada pelo próprio sujeito, uma vez que não existem seres educados e não educados, mas sim que estão sempre em processo de aprendizagem. Nesse sentido, a consciência bancária da educação deve ser combatida, porque nela o educando recebe passivamente conhecimentos, tornando-se um depósito do educador (FREIRE, 1979). O autor ressalta ainda que não se educa o homem para transformá-lo em um arquivo, motivo pelo qual o ser humano perde o poder de criatividade e o espírito de investigação, e passar a ser semelhante uma peça mecânica.

$\mathrm{O}$ ato de ensinar é mútuo, o professor aprende ensinando quando, de forma humilde, aberto, se ache disponível a repensar o pensado, rever-se em suas posições (Freire, 1997). Esse mesmo autor afirma que o aprender é mais que a leitura abstrata dos textos, é necessária a realização de uma leitura do mundo, essa experiência sensorial facilita a leitura das palavras tornando a compreensão do cotidiano mais simples. No entendimento de Maria Montessori, Röhrs, (2010. p. 26) diz que "Nenhuma descrição, nenhuma imagem de nenhum livro podem substituir a vista real das árvores em um bosque com toda vida que acontece em volta delas". Em seu escrito, afirma Röhrs, (2010. p. 20), Montessori não se cansa de ressaltar a importância do empreendimento que consiste em desenvolver atitudes em vez de simples competências; segundo ela, atividade prática deve criar uma atitude, e isso graças à contemplação: "A atitude vem a ser a da conduta disciplinada".

Desde o surgimento da espécie humana, os tipos de impacto ambiental têm se diversificado e intensificado (BRANCO, 2004). Esse autor complementa que à medida que a espécie humana foi desenvolvendo os impactos ambientais foram se ampliando em intensidade e extensão. Um dos grandes alertas internacionais ocorreu com a publicação do livro "Primavera silenciosa", da escritora ecologista Rachel Carsor em 1962, quando a autora divulgou os efeitos danosos exercidos pelos pesticidas e poluentes sobre o meio ambiente e, consequentemente, a perda de qualidade de vida em escala planetária. Essa preocupação seguiu, na mesma década, com a criação do Clube de Roma, um grupo de especialistas de diferentes áreas, empresários e políticos passou a discutir a crise ambiental (BRASIL, 2009). Na década seguinte, em 1972, a Organização das Nações Unidas - ONU promove a I Conferência Mundial Sobre Ambiente Humano, na cidade de Estocolmo, Suécia que culminou com 
uma avaliação dos problemas ambientais globais e na ênfase da Educação ambiental como uma oportunidade para solução da crise planetária, uma vez aliada à participação dos cidadãos (REIGOTA, 2007).

O termo Educação ambiental é definido na Política Nacional de Educação Ambiental (BRASIL, 1999) como o meio pelo qual o indivíduo e a coletividade constroem valores sociais, conhecimentos, habilidades, atitudes e competências voltadas para a conservação do meio ambiente, bem de uso comum do povo, essencial à sadia qualidade de vida e sua sustentabilidade. A participação do Ministério da Educação (MEC) na Conferência Internacional das Nações Unidas para o Meio Ambiente, que ficou conhecida como Eco-92, contribuiu para criação da Carta Brasileira para Educação ambiental, documento que reconhece ser a Educação ambiental o instrumento mais importante para viabilizar a sustentabilidade como estratégia de sobrevivência do planeta e, consequentemente, de melhoria de qualidade de vida humana. Pois no entendimento de Guimarães (2012), a crise ambiental é um consenso mundial. A Carta favoreceu a criação de centros de Educação de ambiental, espaços para formação de cidadãos para interagir em diversas modalidades ensino (BRASIL, 2005). Guimarães (2012, p. 23) destaca a importância da educação na superação dos problemas ambientais.

Dessa forma, sendo a educação um potencial motor das dinâmicas do sistema social, a participação dos educadores nesse debate e na construção de proposta para o enfrentamento dessa crise é fundamental. Essa participação vem sendo estimulada pela própria crença generalizada na sociedade sobre o papel da educação para superação dos problemas ambientais.

A Educação ambiental não possui um conteúdo específico, porém vários, dependendo da faixa etária dos estudantes e do contexto educativo do momento. Mas o conteúdo mais indicado deve ser originado do levantamento da problemática ambiental vivenciada pela comunidade escolar (REIGOTA, 1994).

Embora não seja uma disciplina escolar a Educação ambiental pode ser trabalhada por meio de iniciativas pessoais e de grupos multidisciplinares de professores (MENDES; VAZ, 2009). Entretanto, na legislação brasileira a partir da Constituição Federal a Educação ambiental se tornou obrigatória em todos os níveis de ensino. A Educação ambiental deverá estar presente em todos os níveis de ensino, como tema transversal, sem constituir disciplina específica, como uma prática educativa integrada, envolvendo todos os professores, que deverão ser treinados para incluir o tema nos diversos assuntos tratados em sala de aula (BRASIL, 1997, 1999, 2012). Os Parâmetros Curriculares Nacionais proporcionam aos professores as diretrizes educacionais nacionais de reflexão sobre o trabalho do estudante e, também, diretrizes para a ação (MENDES; VAZ, 2009), de forma que o Ministério da 
Educação determina por meio da Resolução no 02/2012, do Conselho Nacional de Educação CNE (BRASIL, 2012), em seu no artigo 10, que a Educação ambiental seja desenvolvida no ensino médio de forma transversal e integradamente, permeando todo currículo.

Na mesma linha, a Educação ambiental, por sua natureza integradora, perpassa diferentes áreas do conhecimento e pode ser trabalhada dentro dos mais variados contextos. Entre eles, destacam-se as atividades realizadas em áreas que permitem um contato direto com a natureza (TOLEDO; PELICIONI, 2005). Ambientes visitados são chamados de espaços ou estruturas educadoras. Eles visam à promoção de uma aprendizagem continua, e a construção de conhecimento e sentimentos para a Educação ambiental se tonar mais interativa, contextualizada na bioregião, despertando mais interesse sobre aquele espaço que contribui com a conservação ambiental (BRASIL, 2009). As visitas técnicas são essenciais para aproximar os estudantes da prática. Diminuem as distâncias entre os ambientes de aprendizagem com a realidade local. Por meio das referidas visitas, os estudantes podem beneficiarse das experiências dos outros indivíduos que já trilharam caminhos semelhantes (FORTUNATO; NEFFA; MIRANDA, 2012). A realização dessas atividades como instrumentos para o desenvolvimento da Educação ambiental não deve ocorrer de forma pontual e caracterizada apenas pelos aspectos ecológicos, todavia é necessário ocorrer como atividade permanente, que enfatize também aspectos econômicos, sociais, políticos, culturais e éticos, abrindo um espaço para geração de novos valores de respeito aos seres humanos e à vida (TOLEDO; PELICIONI, 2005). Desta forma, podemos dizer que a Educação ambiental transcende a perspectiva da abordagem de conteúdos das Ciências Naturais. Ela deve englobar aspectos socioeconômicos, políticos e culturais (LAYRARGUES, 2012).

\section{Métodos}

Foram realizadas atividades práticas com temáticas ambientais, durante $0^{2}$ semestre de 2013, com estudantes do Curso Técnico em Meio Ambiente da modalidade integrada do Instituto Federal de Educação, Ciência e Tecnologia do Amapá, campus Laranjal do Jari, a 270 km de Macapá - AP. Para delimitação do grupo "experimental" foi sorteada uma das duas turmas da primeira série de Meio ambiente (MAB 1B), com 24 estudantes. Para compor 0 grupo comparativo, denominado "controle", foi utilizada a segunda turma, "MAB $1 A^{\prime \prime}$, com 27 estudantes. Ambas as turmas foram formadas por estudantes dos gêneros masculino e feminino, matriculados de maneira aleatória, de origem predominantemente urbana, que apresentavam a mesma faixa etária, oriundos de escolas públicas da região e, em tese, apresentavam o mesmo perfil socioeconômico.

A natureza do estudo foi quali-quantitativa, e os dados foram coletados através de questionários ("pré-teste e pós-teste"). Esses questionários foram 
padronizados e continham questões fechadas, de múltiplas alternativas, e abertas, visando identificar aspectos relacionados ao conhecimento prévio de cada estudante. Os estudantes pertencentes ao grupo experimental foram submetidos a um processo pedagógico distinto da grade curricular habitual, baseado em ações educativas envolvendo teoria e práticas contextualizadas, reflexivas e baseadas na sensibilização. Foram realizadas atividades educativas sobre as temáticas: 1) importância da água (Figura 1); 2) gerenciamento dos resíduos sólidos; e 3) uso inadequado das margens de um rio pelo processo de urbanização, com base na metodologia do projeto Florestabilidade (2012).

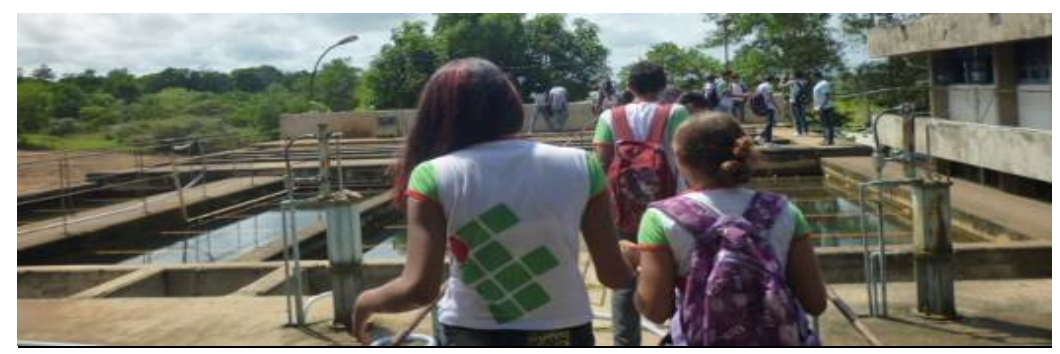

Figura 1: Visita técnica realizada na Estação de Tratamento de Água com 24 estudantes pertencentes ao grupo experimental do Curso Técnico em Meio Ambiente do Instituto Federal do Amapá, campus Laranjal do Jari. Agosto de 2013. Fonte: autoria própria.

Durante as visitas técnicas os estudantes foram orientados a promoverem perguntas para servidores dos locais visitados, bem como a pessoas que se utilizavam de resíduos do lixão (Figura $2 a$ e b). Além disso, foram incentivados a fazerem fotografias ou filmagens das condições observadas, juntamente com anotações de dados que fossem de interesse.

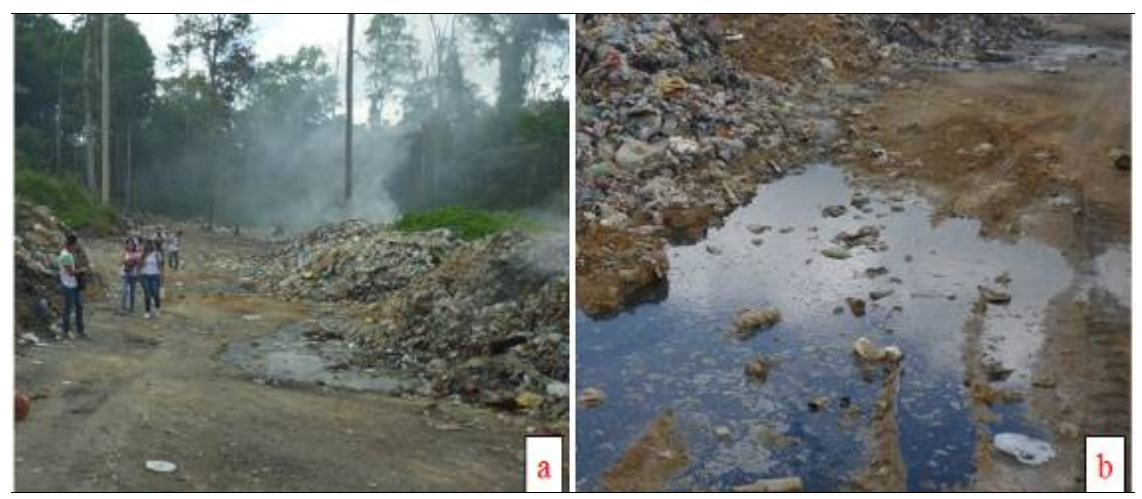

Figura 2a e b: Visita técnica realizada no lixão a céu aberto em Laranjal do Jari. (a) Presença de fumaça resultado da queima de resíduos sólidos e possíveis emissões de gases tóxicos. (b) Água empoçada formada a partir do acumulo de chorume presentes nas pilhas de resíduos sólidos e possíveis fonte de contaminação do lençol freático. Setembro de 2013.

Fonte: autoria própria. 
Em sala de aula, após cada atividade de campo os estudantes fizeram a avaliação da visita técnica. Essa avaliação consistiu em explanar o que foi observado durante a prática pedagógica no ambiente externo, contextualizando espacial e temporalmente, criando um processo de reflexão coletiva a respeito dos problemas observados e de ações necessárias para eventual solução dos mesmos. Os estudantes foram incentivados a tomarem atitudes individuais, coletivas, técnicas e cidadãs.

Paralelamente às aulas curriculares tradicionais, no intervalo entre as visitas técnicas, os estudantes assistiram aos filmes: "Janela Natural", referente à temática importância da água (JANELA..., [200-?]); "The Story of Stuff" (A História das Coisas), com a temática associada à produção de bens e descarte de resíduos (A HISTÓRIA..., 2005); "Ilhas das Flores", referentes ao gerenciamento dos resíduos sólidos (ILHAS..., 1989); e "Nascentes Protegidas", sobre a proteção de áreas de preservação permanente (NASCENTES..., 2010). Os temas abordados possibilitaram uma abordagem que partiu de uma visão mais geral das problemáticas para as questões locais

$\mathrm{Na}$ temática do "gerenciamento de resíduos sólidos" os estudantes participaram de um ciclo de palestras intitulado "Resíduos tecnológicos: uma visão transdisciplinar". No evento foram abordados os temas " $A$ física $e$ a mecânica quântica", "A biologia e a toxidade dos metais pesados", "Meio ambiente e Resíduos Sólidos", "Lixos espaciais" e "Resíduos eletrônicos"; ministrados pelos professores de Física, Biologia, Meio ambiente, Geografia e Informática. A temática sobre a ocupação das margens do rio pelo processo de urbanização foi realizada a partir de uma atividade fluvial. Nessa, os estudantes embarcados visitaram um trecho do rio Jari, partindo da orla da cidade no sentido contrário ao fluxo do rio, até a área do campus Laranjal do Jari. Essa atividade discutiu aspectos do assoreamento do rio, da contaminação por resíduos sólidos e o processo de urbanização da cidade (Figura 3a e b).

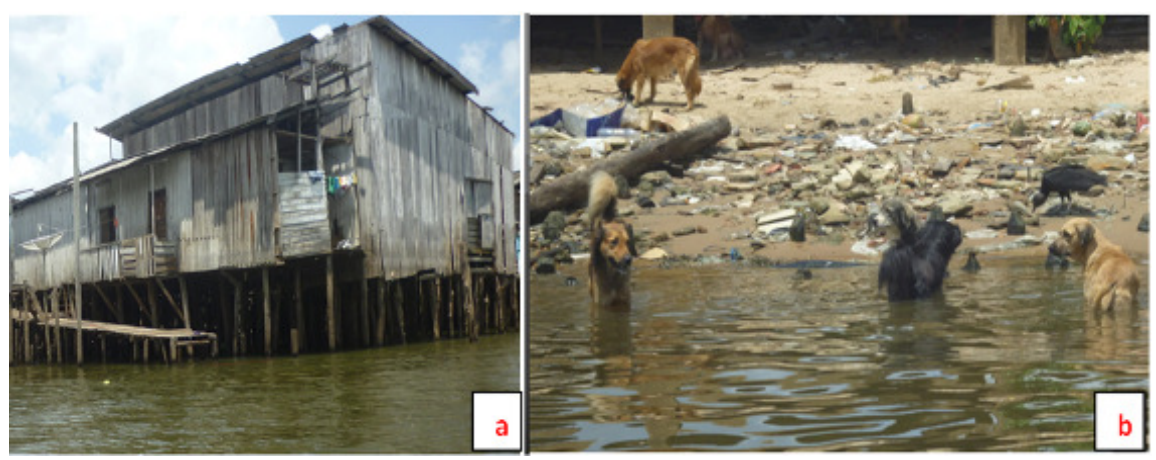

Figura 3a e b: Margem esquerda do Rio Jari ocupada por palafitas. Nesse tipo de residência os dejetos são liberados no rio e a mesma água serve para lazer e uso doméstico. (b) Presença de animais e resíduos sólidos orgânico em decomposição. Novembro de 2013. Fonte: autoria própria. 
Em sala de aula foi relembrada a visita técnica, a partir da apresentação ilustrada dos problemas observados e, em seguida, os estudantes em grupo elaboraram propostas de soluções. Essas possíveis soluções tinham como base as informações levantadas nas aulas teóricas e atividades práticas e objetivavam o envolvimento dos estudantes como agentes de plena cidadania. Em cada atividade foram realizadas observações do comportamento individual e em grupo que serviram para subsidiar resultados quantitativos e discussões.

Após a realização do ciclo de atividades foi aplicado aos estudantes do grupo experimental e do grupo controle o segundo questionário: "pós-teste". A análise de dados foi realizada com auxílio do programa estatístico BioEstat 5.0 (AYRES et al., 2007). Os testes utilizados nos questionários foram os nãoparamétricos: Qui-Quadrado $\left(\mathrm{X}^{2}\right)$, Wilcoxon e Kappa.

\section{Resultados}

Os resultados obtidos por amostras independentes ou relacionadas, dimensionou a percepção e a compreensão dos estudantes sobre as questões ambientais abordadas. Considerando a pergunta "o que faz parte do meio ambiente?", as alternativas de respostas foram compostas por elementos representantes da natureza e da sociedade (Figura 4).

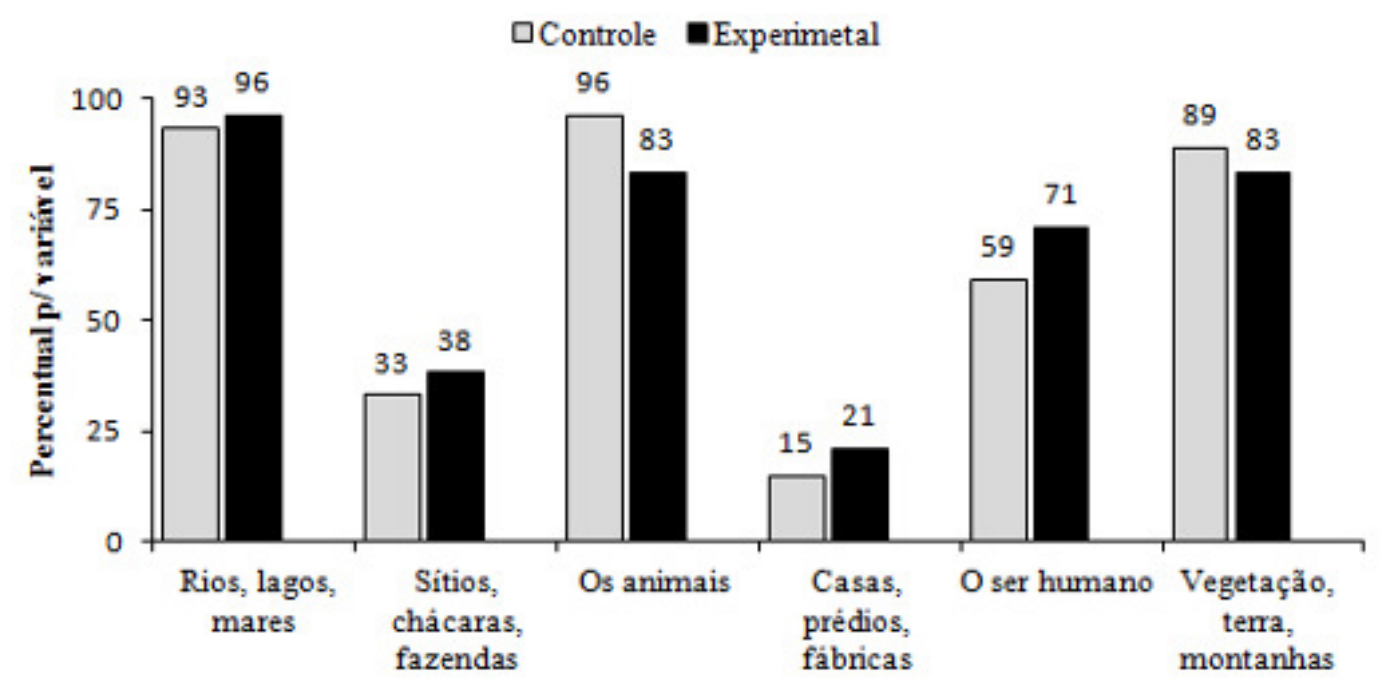

Alternativas marcadas pelos estudantes

Figura 4: Resultado do pré-teste realizado com os estudantes do Instituto Federal do Amapá, campus Laranjal do Jari, pertencentes aos grupos: experimental $(n=24)$ e controle $(n=27)$, sobre os elementos que fazem parte do meio ambiente. Jun. 2013. 
Em ambas as turmas, as opções mais marcadas como elementos do meio ambiente foram: rios, lagos e mares; animais; vegetação, terra e montanhas. As opções menos marcadas foram àquelas estritamente relacionadas à sociedade como casas, prédios e fábricas; sítio, chácaras e fazendas; e o ser humano. A comparação entre a turma controle e a experimental, que participou do projeto não apresentou diferenças significativas, seja no pré-teste $\left(x^{2}=3,59\right.$ e $\left.p=0,6086\right)$, seja no pós-teste $\left(x^{2}=\right.$ $42,74$ e $p=0,5107)$. A turma experimental também não apresentou diferenças significativas entre o momento anterior e o posterior ao projeto (" $\mathrm{t}$ " Wilcoxon = $0,2697 ; p=0,7874)$. Isso sugere o predomínio e a permanência da visão reducionista do conceito de Meio ambiente, visto que os estudantes continuaram dando mais ênfase aos elementos que compõem a "natureza", tanto antes quanto após as atividades curriculares regulares e/ou do projeto.

Para avaliar a percepção dos problemas ambientais vivenciados a nível local, regional e global, os estudantes responderam a pergunta "o que você considera como um problema ambiental?" Os estudantes foram orientados, caso desejassem, a marcar mais de uma das opções apresentadas. Dentre as opções apresentadas no pós-teste, a poluição das águas foi marcada por todos os participantes do estudo. Receberam também elevado percentual de marcação as opções: desmatamento e queimadas (100\% para o grupo controle e $90 \%$ para o grupo experimental); esgoto não tratado (83\% controle e $75 \%$ experimental); lixão (75\% controle e $85 \%$ experimental); extinção de animais e vegetais (75\% controle e $85 \%$ experimental). No entanto, receberam baixos percentuais de marcação as opções: poluição sonora e visual (13\% controle e $20 \%$ experimental); enchentes e falta de água (33\% controle e $30 \%$ experimental). A pouca importância para essa última opção pode estar relacionada à perenidade do Rio Jari, manancial de onde é captada a maior parte da água para tratamento e distribuição em Laranjal do Jari e municípios circunvizinhos e, provavelmente, não reflete a crise hídrica da região Sudeste registrada a partir de 2014.

$\mathrm{O}$ resultado obtido não apresentou diferenças, tanto no pré-teste $\left(\mathrm{X}^{2}=\right.$ $15,467$ e $p=0,1159)$, quanto no pós-teste $\left(X^{2}=14,619\right.$ e $\left.p=0,1466\right)$, indicando uma ampliação não significativa do conhecimento medido sobre 0 que pode ser considerado "um problema ambiental", seja pelas ações do projeto experimental, seja pela grade curricular regular. Os estudantes percebem parte dos problemas a nível local, como esgoto não tratado e lixão a céu aberto. Porém, não reconhecem a poluição visual, associadas aos resíduos sólidos nas vias públicas; nem a poluição sonora, provenientes propagandas, manifestações culturais e religiosas; como problemas vivenciados pela população do município de Laranjal do Jari. Também não associaram eventuais enchentes às alterações em termos de ocupação e uso do espaço pela população humana. $E$, de fato, a dinâmica de flutuação natural do nível do rio na região favorece tal concepção. 
Em relação aos resíduos sólidos, os estudantes responderam a pergunta "o que você acha necessário para solucionar os problemas causados pelo excesso de lixo?". No pós-teste do grupo experimental, 100\% dos estudantes marcaram a alternativa "reciclar"; seguida por "reutilizar materiais" (85\%) e por "mudança de atitudes das pessoas" (80\%). No entanto, $30 \%$ marcaram a alternativa de mais lixões e a contratação de mais garis, sugerindo que a concepção de "limpar" e "jogar no lixo" ainda são consideradas importantes soluções para a geração de resíduos. No grupo controle, como possíveis soluções, 92\% marcaram "reciclar" e "mudança de atitudes das pessoas", e 83\% "reutilizar materiais". Isso sugere que ambos os grupos obtiveram informações mais qualificadas e trabalharam os conceitos de forma efetiva, o que pode ser associado à política dos três erres (3Rs): reutilizar, reduzir e reciclar; conhecida no âmbito de nossa sociedade. O resultado da comparação do grupo experimental, antes e depois e depois do projeto (" $\mathrm{t}$ " Wilcoxon $=2,5205 ; p=0,0117$ ), atestou a concepção de aprofundamento significativo sobre a temática. Como mecanismo para amenizar problemas ambientas causados por resíduos sólidos, no pós-teste, $50 \%$ dos estudantes do grupo experimental consideram a alternativa de "reduzir o consumo"; $55 \%$ as "mudanças do modo de produção e consumo" e "mais projetos e campanhas de Educação ambiental", indicando relativa compreensão de que a problemática do lixo vai além da coleta e destinação adequada de resíduos.

Em se tratando de fenômenos naturais causados por chuva os estudantes tiveram que responder à seguinte pergunta "sobre as enchentes, que ações podem minimizar ou evitar as mesmas?” (Figura 5).

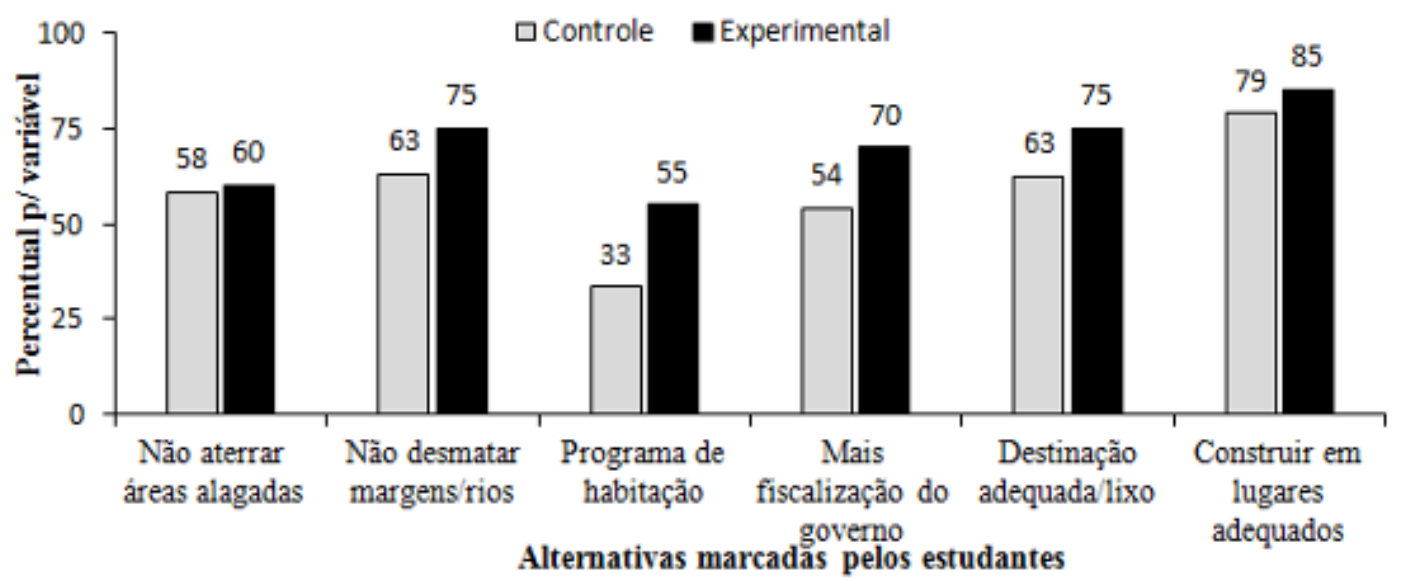

Figura 5: Resultado do pós-teste realizado com os estudantes dos grupos: experimental $(n=20)$ e controle $(n=24)$ da primeira série do Curso Técnico em Meio Ambiente, do Instituto Federal do Amapá, campus Laranjal do Jari, sobre como evitar ou amenizar efeitos de enchentes. Novembro de 2013. 
No grupo experimental, as alternativas de "construir em lugares adequados" (85\%); "não desmatar margens dos rios" e "destinar adequadamente o lixo" (75\%) apresentaram percentuais mais altos do que no controle, o que foi associado às atividades do projeto. Reforçando tal assertiva, as demais alternativas relacionadas às medidas mitigadoras foram marcadas por pelo menos metade dos estudantes no grupo experimental e no caso de programas de habitação, por cerca de um terço no grupo controle. O resultado obtido no pré-teste, comparando o grupo controle com o experimental, apresentou diferença significativa $\left(X^{2}=11,944 ; p=0,0356\right)$, com destaque positivo em termos cognitivos para o controle. Entretanto, após as atividades desenvolvidas com o grupo experimental, tais diferenças não foram mais observadas (pós-teste: $X^{2}=3,571$ e $p=0,6127$ ). Tal fato corrobora a concepção de evolução cognitiva significativa do grupo experimental. Isso aponta que a temática foi abordada e assimilada de forma distinta, comparando o projeto e a grade curricular regular; e que a proposta experimental apresentou maior eficácia cognitiva em termos comparativos.

Os estudantes foram questionados se "de acordo com a forma que sociedade utiliza suas águas, você acha que um dia a água acabará?". Os grupos, experimental e controle, marcaram $85 \%$ e $63 \%$, respectivamente, para a opção que afirma que a água não acabará enquanto substância inorgânica, visto que o ciclo natural da água possibilitará sua perenidade. Para esses estudantes, o que poderá acabar será a água potável. Porém, no grupo controle, 37\% acreditam que a água acabará em razão do mau uso (Figura 6).

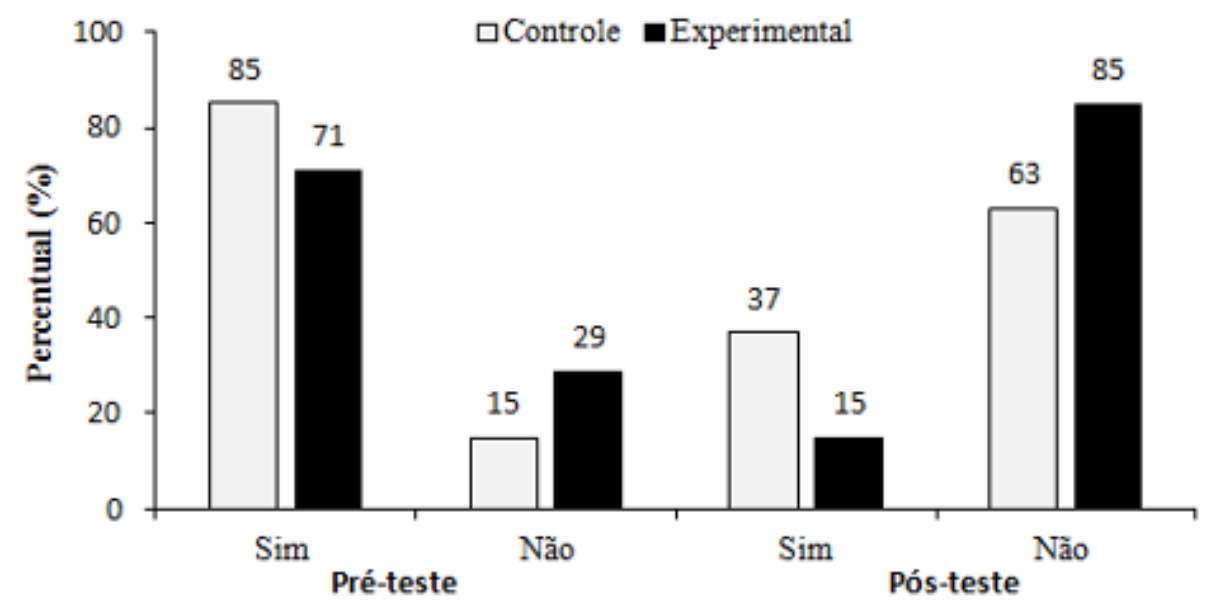

Figura 6: Resultados do pré e pós-teste realizados com os grupos: experimental $(n=20)$ e controle ( $n=24)$, sobre a pergunta "de acordo com a forma que sociedade utiliza suas águas, você acha que um dia a água acabará?". Estudantes do Instituto Federal do Amapá, campus Laranjal do Jari. Novembro de 2013.

Quando comparados os grupos controle e experimental foram identificadas diferenças significativas, tanto no pré-teste $\left(X^{2}=5,711\right.$ e $p=$ 
0,0265), quanto no pós-teste $\left(X^{2}=12,578\right.$ e $\left.p=0,0007\right)$. Também foram identificadas diferenças significativas quando analisado o grupo experimental, antes e depois do projeto ("t" Kappa $=0,5600 ; p<0,0001$ ). $\mathrm{O}$ conjunto de observações aponta que esse tema é relativamente bem trabalhado, tanto pela grade curricular regular, quanto pela proposta alternativa. E que, apesar de serem perceptíveis os avanços cognitivos em ambas as propostas pedagógicas, é significativa a distinção proporcionada pelas ações do projeto.

Quanto aos resíduos sólidos os estudantes foram questionados sobre "qual é o destino do lixo produzido no município onde você mora?" (Tabela 1).

Tabela 1: Resultado dos pré e pós (teste) realizados com estudantes pertencentes aos grupos experimental e controle, sobre o destino dos resíduos sólidos produzidos no município em que mora. Estudantes do Instituto Federal do Amapá, campus Laranjal do Jari.Junho (antes) e novembro (depois) de 2013.

\begin{tabular}{lcccc}
\hline \multirow{2}{*}{ VARIÁVEL } & \multicolumn{2}{c}{ FREQUÊNCIA RELATIVA DAS RESPOSTAS (\%) } \\
\cline { 2 - 5 } & \multicolumn{2}{c}{ Antes } & \multicolumn{2}{c}{ Depois } \\
\cline { 2 - 5 } & Controle & Experimental & Controle & Experimental \\
\hline Aterro sanitário & 7,4 & 12,5 & 8,3 & 5,0 \\
\hline Aterro controlado & 3,7 & 0,0 & 0,0 & 0,0 \\
\hline Lixão à céu aberto & 66,7 & 54,0 & 75,0 & 95,0 \\
\hline Desconhece o assunto & 22,2 & 33,5 & 16,7 & 0,0 \\
\hline Total & $\mathbf{1 0 0 , 0}$ & $\mathbf{1 0 0 , 0 0}$ & $\mathbf{1 0 0 , 0}$ & $\mathbf{1 0 0 , 0}$ \\
\hline
\end{tabular}

Fonte: autoria própria.

Em termos de percepção sobre o destino do lixo, o "lixão a céu aberto" recebeu maior percentual de marcação. Nesse aspecto, o grupo experimental ampliou sua percepção, aumentando de $54 \%$ no pré-teste para $95 \%$ no pósteste. Nesse grupo, o desconhecimento sobre o assunto caiu de 33,5\% para $0 \%$, evidenciando que as atividades pedagógicas interferiram positivamente na ampliação do conhecimento sobre a realidade vivenciada pelos estudantes nas proximidades de suas moradias. Comparativamente tais resultados destacam que o projeto experimental foi bastante mais efetivo que a grade curricular regular na abordagem da problemática do lixo.

\section{Discussão}

A análise qualitativa dos dados deixou clara a ampliação cognitiva sobre o meio ambiente ao longo do projeto. Ainda em termos qualitativos, foi significativa a evolução por parte do grupo experimental, quando a temática foi abordada a partir de problemas do cotidiano. Apesar das limitações inerentes às formas de obtenção e interpretação de aspectos (parciais) da realidade, a análise qualitativa pode ser uma importante e complementar forma de avaliar o processo educacional. Ela "exige do pesquisador uma capacidade integrativa e analítica que, por sua vez, depende do desenvolvimento de uma capacidade 
criadora e intuitiva" (MARTINS, 2004, p. 292). Já a avaliação qualitativa pretende ultrapassar a quantitativa, complementando-a e contribuindo em suas interpretações. Ela entende que, para a interpretação do espaço educativo, os processos são mais relevantes que os produtos, não fazendo jus à realidade, se a mesma for reduzida às manifestações empiricamente mensuráveis (DEMO, 2004 apud CHUEIRI, 2008, p. 49-69). Sinteticamente, a hipótese de que "atividades de Educação ambiental planejadas e incluídas na rotina formal de aulas conduzem a maior percepção e compreensão a respeito das questões ambientais e de problemas que os estudantes vivenciam em sua localidade", foi corroborada, tanto pelas análises quantitativas, quanto pelas observações qualitativas.

Em relação à compreensão do conceito de meio ambiente, a pergunta "o que faz parte do meio ambiente?' apresenta opções que compõem a natureza e a sociedade, e era esperado, ou melhor, desejado, que as respostas dos estudantes contemplassem aspectos mais amplos do tema, e não refletissem pontos de vista reducionistas. Essa expectativa foi baseada no fato que, além das atividades do projeto, esses estudantes fazem o curso Técnico de Meio Ambiente. Além disso, na época da execução do projeto, os mesmos estavam cursando a disciplina de Gestão Ambiental, que se propõe a apresentar questões ambientais com um enfoque mais amplo que aquele habitualmente trabalhado nas Ciências Naturais e nas Ciências Biológicas. Vale ressaltar que durante a aplicação dos questionários ouvia-se a frase "meio ambiente é tudo". Entretanto, esse "tudo" não contemplou com propriedade os ambientes de moradia, casa, prédio, sítio, chácaras, fazendas e fábricas. Esses conceitos não foram efetivamente incluídos como parte do meio ambiente, o que caracteriza a permanência do predomínio da visão reducionista. Essa ideia é corroborada por Layrargues (2002), quando o autor afirma que "apesar da complexidade do tema, muitos programas de Educação ambiental na escola são implementados de modo reducionista".

O tema "Meio ambiente" é habitualmente trabalhado no ensino fundamental, concentrando esforços em momentos pontuais, como datas comemorativas, e não considerando o tema como deveria ser tratado, de maneira transversal (BRASIL, 1997). Além disso, essas atividades de envolvimento "ambiental" apresentam apenas um caráter preservacionista, em sentido mais restritivo (DIEGUES, 2001). Isso pode ser identificado, por exemplo, no "dia da árvore", no qual a palavra de ordem é "plante uma árvore"; ou se a problemática a ser trabalhada é a água, a frase é "não desperdice água"; ou ainda, na semana do meio ambiente se enfatiza a frase "preserve os animais". Essa forma de abordagem não é baseada em discussões críticas contínuas, cumulativas e contextualizadas, com adequada reflexão social e política da maneira como tais aspectos afetam nossa sociedade. À essa maneira simplista de se desenvolver o tema meio ambiente, Layrargues (2012) rotula de "Educação ambiental conservadora" ou, sob nosso ponto de vista, acrítica uma vez que ela enfatiza uma visão meramente restritiva do meio 
ambiente, na qual ele se resume apenas aos elementos da natureza e, mesmo nesse caso, à alguns elementos, os mais midiáticos.

Quando considerada a pergunta "o que você considera um problema ambiental', a diversidade de alternativas buscou identificar problemas pontuais e, ao mesmo tempo, identificar a dimensão mais ampla associada ao conceito. Entretanto, visto que não foram identificadas diferenças significativas entre 0 grupo controle e o experimental ao final do projeto, acreditamos que isso esteja associado à citação de problemas mais conhecidos, mais genéricos e, por contraste óbvio, ao relativo desconhecimento sobre o assunto. Nesse último caso, podemos citar a poluição sonora e a poluição visual, pois ambas receberam baixos percentuais de marcação. Via de regra, tais temas são pouco ou mesmo não abordados, tanto nos meios formais quanto informais. Segundo Bastos (2012), a sociedade não tem conhecimento do que é de como podemos evitá-la. Entretanto, a poluição sonora é um problema ambiental que afeta um grande número de pessoas, ficando atrás somente da poluição do ar e das águas (QUADROS, 2004). Apesar de legislação restritiva é evidente a comum emissão de ruídos intensos, proveniente de atividades sociais, culturais, comercias, industriais, recreativas, propagandas eleitorais etc., que afetam a população (BASTOS, 2012; PEREIRA; SILVA; SALES, 2011). Essa temática também não foi abordada especificamente pelo projeto.

Todos os estudantes apontaram que a poluição aquática é um problema ambiental. Entretanto, numericamente não foi possível identificar diferenças significativas entre os dois grupos. Possivelmente tal condição está associada ao fato do tema "água" ser mais habitualmente abordados em programações pontuais, como o dia água, que costuma fazer parte de calendários pedagógicos. Considerando o grupo experimental, o fato do tema ter sido profundamente trabalhado no âmbito do projeto - a visita técnica realizada à Companhia de Água e Esgoto do Amapá - CAESA permitiu aos estudantes trazerem para o concreto a temática "água", através da observação dos processos de captação, tratamento e distribuição da água - a intensa relação dos estudantes com o técnico da CAESA, possibilitou a compreensão de conceitos e a clara associação dos mesmos com problemas do cotidiano. $\mathrm{Na}$ concepção de Freire (1997), "É desvelando o que fazemos desta ou daquela forma, à luz de conhecimento que a ciência e a filosofia oferecem hoje, que nos corrigimos e nos aperfeiçoamos. É a isso que chamo pensar a prática e é pensando a prática que aprendo a pensar e a praticar melhor". O mesmo autor diz ainda (FREIRE, 1997, p.70):

E quanto mais penso e atuo assim, mais me convenço, por exemplo, de que é impossível ensinarmos conteúdos sem saber como pensam os alunos no seu contexto real, na sua cotidianeidade. Sem saber o que eles sabem independentemente da escola para que os ajudemos, a saber, melhor o que já sabem, de um lado e, de outro, para, a partir daí, ensinar-lhes o que ainda não sabem. 
Dificuldades para a realização de atividades externas existem. Pode ser necessário o transporte para o deslocamento dos estudantes, a autorização institucional para visitar determinada área ou empresa, a conciliação com os horários regulares de aulas em sala, a disponibilidade de docentes para participar de ações interdisciplinares, dentre outros. Para viabilizar tais propostas, buscar soluções que sirvam para o coletivo dos professores e desenvolver procedimentos para minimizar dificuldades da realização de atividades didáticas em ambientes externos deve estar entre as prioridades dos setores pedagógicos e administrativos das instituições de ensino. Isso é fundamental para viabilizar, agilizar, aperfeiçoar e incorporar tais práticas no cotidiano escolar. Respostas positivas por parte dos responsáveis e o entusiasmo dos estudantes em participar de atividade dessa natureza - fora da rotina diária da escola - são pontos muito positivos e devem ser levados em consideração. Entretanto, esses aspectos não podem ser mensurados quantitativamente, sendo ainda de difícil dimensionamento qualitativo.

As experiências realizadas em sala de aula, os simuladores dos quantitativos de água existente no planeta: indisponível, disponível e potável; e do desperdício de água por gotejamento em torneira mal fechada; além de ser apresentado e discutido um vídeo sobre o tema; a compreensão a respeito do assunto subsidiou a derrubada de um mito - a impossibilidade de esgotamento da água potável - que apresenta um forte caráter local, por razões de natureza regional e cultural. Isso ocorreu mesmo antes desta questão estar no cotidiano midiático a partir de 2014. Tais práticas foram essenciais para ampliação de conhecimentos em relação à água. Na turma experimental, junto com a visita técnica à estação de tratamento de água, as demonstrações e os debates em sala proporcionaram uma evolução significativa, quando comparados o "antes" e o "após" o projeto. No entanto, tais atividades demandam significativo tempo pedagógico e, uma vez que os estudantes submetidos à nova proposta não disponibilizavam de tempo livre, o trabalho teve que ser desenvolvido em associação ao conteúdo formal da disciplina de Biologia. Esse aspecto não é necessariamente negativo, mas demanda o planejamento adequado.

A alternativa "lixão" também foi identificada como um problema ambiental, porque recebeu elevada porcentagem de marcação. No pré-teste, o grupo experimental evolui de $71 \%$ para $85 \%$ após participação das atividades. Com relação à evolução, ela reflete um claro resultado das atividades pedagógicas do projeto. A visita técnica ao lixão de Laranjal do Jari e o debate sobre o vídeo Ilha das flores (ILHAS..., 1989), que reporta o descarte de resíduos sólidos de maneira inadequada, associando-o à desigualdade social e às condições desumanas de vida de pessoas; foram essenciais para esse sucesso. Além disso, os estudantes assistiram ao vídeo $A$ História das Coisas (A HISTÓRIA..., 2005), que trata com clareza da questão da produção, descarte, poluição, da economia dos materiais, e também do valor, distorcido, que o consumismo tem hoje na sociedade, considerando ainda suas consequências ambientais e sociais. Dessa forma, conforme esperado, 
observamos, inclusive quantitativamente, a ampliação e o aprofundamento cognitivo a respeito do tema produção e descarte de lixo. A influência positiva que estudantes do grupo controle apresentaram possivelmente está relacionada aos conteúdos de "gestão ambiental", parte da grade curricular específica do primeiro ano do Curso Técnico em Meio Ambiente. Ainda na temática de lixo, em sala de aula foram abordadas doenças transmitidas por vetores, poluição atmosférica decorrente da queima de resíduos sólidos, contaminação do lençol freático e do solo, com base em conceitos de Ecologia e Conservação (e.g. PRIMACK; RODIGUES, 2001; RICKLEFS, 2012).

Durante a visita técnica, dentre as perguntas realizadas pelos estudantes aos catadores de lixo, a que mais chamou atenção foi a seguinte: "o que vocês acharam da presença dos estudantes do instituto nesse ambiente e qual a mensagem que vocês querem que seja repassada aos outros estudantes?". Os catadores responderam que estavam alegres com a sensação de também serem "pessoas". Apesar de obviamente eles serem pessoas, a função que exercem os tornam invisíveis conforme Velloso (2008, p. 1959).

"Descobri que um simples bom dia, que nunca recebi como gari, pode significar um sopro de vida, um sinal da própria existência". O psicólogo sentiu, na [própria] pele, o que é ser tratado como um objeto e não como um ser humano.

emocionaram demasiadamente, devido às cenas envolvendo famílias extremamente carentes, que dependiam de restos de alimento para sobreviver. No filme $A$ História das Coisas foi evidente o interesse dos estudantes em anotar informações e dados gerais sobre resíduos sólidos; utilização inadequada de recursos naturais; consumismo; obsolescência planejada e perceptiva; exploração do trabalho infantil e reciclagem. Além dos vídeos supracitados, da visita técnica realizada e, considerando que os estudantes participaram de um ciclo de palestra sobre "resíduos", o tema produção e descarte de lixo foi bastante explorado pela proposta pedagógica. Tais atividades certamente influenciaram positivamente na resposta da pergunta "qual é o destino do lixo produzido no município onde você mora" uma vez que os estudantes obtiveram uma evolução de $54 \%$ no pré-teste para $95 \%$ no pósteste, marcando a alternativa "Lixão a céu aberto". Os estudantes compreenderam ainda que o método de destinação de resíduos sólidos a céu aberto apresentava um prazo determinado em lei para se transformar em aterro sanitário, visto que esse é o método de disposição final ambientalmente mais adequado, conforme a Política Nacional de Resíduos (BRASIL, 2010).

A visita técnica na orla da cidade, sobre o Rio Jari foi uma atividade bastante eficaz do ponto de vista pedagógico. Associada ao questionamento "Sobre as enchentes, que ações podem minimizar ou evitar as mesmas?", os 
estudantes compreenderam com clareza que: ações educativas individuais e/ou coletivas, ações governamentais, o aterramento de áreas eventualmente alagáveis, o desmatamento das margens dos rios, o destino adequado de resíduos sólidos, dentre outros, estão relacionados com eventuais enchentes.

Essa proposta pedagógica pode e deve ser executada em outros institutos federais e escolas, independentemente da faixa etária, modalidade de ensino e série. As saídas para ambientes externos tornam a escola dinâmica, aproximando a teoria da prática, enfatizando o conhecimento da realidade local e dando aos estudantes uma oportunidade diferente de ver o mundo. A visita técnica é o procedimento mais viável para ir além dos muros da escola, e para ampliação da eficácia das atividades didáticas, sem afetar o calendário escolar. Recomendamos pelo menos uma visita técnica por bimestre, preferencialmente envolvendo mais de uma disciplina, visto que, no entendimento de Maria Montessori (apud. RÖHRS, 2010), "nenhuma imagem de livro substitui a vista do real do ambiente". Outra maneira de enriquecer o conhecimento sobre a temática ambiental é ir além dos muros escolares por meio virtual, incluindo nos momentos entre as visitas técnicas, sessões de vídeos e/ou documentários, se possível, também produzidos pelos próprios estudantes.

\section{Conclusão}

A turma que participou do projeto obteve resultados qualitativos consideráveis, considerando a proposta aplicada. Entretanto, resultados que envolvem sentimentos, emoções e afeto, apesar de evidentes, não foram própria ou adequadamente avaliados. Considerando as circunstâncias do contexto local para regional, os estudantes ampliaram a compreensão e percepção sobre a realidade que os cerca à medida que ultrapassaram os muros da escola e vivenciaram ambientes naturais acometidos por problemas ambientais. Quando comparado os dois grupos (controle e experimental), assim como os momentos antes e depois, foram identificadas diferenças significativas. Entretanto, alguns resultados contribuem para dimensionar a dificuldade de se quebrar o paradigma adotado pela escola em geral, da condução de uma Educação ambiental conservadora, em detrimento de uma Educação ambiental crítica.

Os estudantes interagem facilmente e demonstram grande interesse na busca de soluções, quando os assuntos tradados em sala de aula fazem parte de seu cotidiano. E tudo pode ser realizado em consonância com os conteúdos dos componentes curriculares. A escola precisa se repensar, sobretudo porque, em geral, faz parte de comunidades que apresentam variados e significativos problemas socioambientais. Para desenvolver a educação ambiental com êxito no âmbito formal, cada docente deve estar disponível a "repensar o pensado, rever-se em suas posições" (FREIRE, 1997). Tal reflexão se torna fundamental, uma vez que as práticas de Educação ambiental devem ir além dos conteúdos dos componentes curriculares. A relação entre escola e 
comunidade necessita de maior aproximação. A comunidade envolve todos os setores como empresas que fornecem serviços básicos à população (água, energia, saneamento básico, transporte, saúde e educação, segurança pública etc.), órgãos de defesa do meio ambiente, de defesa do consumidor, de segurança alimentar, os poderes executivo, legislativo e judiciário e o terceiro setor. Essa aproximação é de grande relevância, pois parte da comunidade está totalmente alheia ao papel das instituições de ensino e essa desarticulação dificulta enormemente práticas de educação ambiental crítica e as necessárias mudanças em nossa sociedade.

\section{Agradecimentos}

Agradecemos ao Instituto Federal do Amapá e à Universidade Federal Rural do Rio de Janeiro, pela oportunidade dada ao primeiro autor para participar, como discente, do Programa de Pós Graduação em Educação Agrícola da UFRRJ. Agradecemos ao Dr. Alexandre de Gusmão Pedrini e ao Dr. Lenício Gonçalves pelas críticas e considerações realizadas em versões preliminares deste texto. Agradecemos aos servidores do Instituto Federal do Amapá, campus Laranjal do Jari, professores: Vinícius Campos, Karoline Siqueira, Raimundo Neto, Leonardo Lima, Elys Mendes, Rafael Costa, Willians de Almeida, Ednaldo Chagas, Maurício Oliveira, Luis Lima, Fernando Rocha, Ângela Utzig, Hanna Patrícia, Marcos Quintários e aos técnicos administrativos: Cláudio Paes, Jocássio Barros, Antônio Nascimento, Sivaldo Souza e Vandson Pedrada; pelo auxílio em diferentes etapas do projeto. Agradecemos aos estudantes do IFAP, pois o interesse em aprender e, em especial, o envolvimento da turma na qual a proposta pedagógica foi aplicada foram fundamentais para o adequado desenvolvimento e para o sucesso deste projeto.

\section{Referências}

A HISTÓRIA DAS COISAS. PRODUCER ERICA PRIGGEN. DIRECTOR LOUIS FOX. OAKLAND, CALIFÓRNIA (EUA): FREE RANGE STUDIOS. 2005. Documentário (21'18"), son., color. Disponível em <https://www.youtube.com>. Acesso em: 14 jun. 2014.

ABBAGNANO, N. Dicionário de filosofia. São Paulo: Martins Fontes, 2003.

AMAPÁ (Estado). Código ambiental do estado do Amapá. Macapá: Secretaria de Estado do Meio Ambiente, 1999.

AMAPÁ (Estado). Lei complementar no 005, de 18 de agosto de 1994. Institui o Código de Proteção ao Meio Ambiente do Estado do Amapá e dá outras providências. Disponível em:<http://www.al.ap.gov.br> Acesso em: 13 jun. 2014. 
AMAPÁ (Estado). Lei no 1.149, de 03 de dezembro de 2007. Dispõe sobre limites na produção de poluição sonora no âmbito do Estado do Amapá e dá outras providências. Disponível em: <http://al.ap.gov.br>. Acesso em: 13 jun. 2014.

AYRES, M. et al. BIOESTAT 5.0 - Aplicações estatísticas nas áreas das ciências bio-médicas. Belém, PA: IDS Mamiraua. 2007.

BASTOS, A. M. Diagnóstico e análise da poluição sonora no município de Macapá/AP. In: SIMPÓSIO NACIONAL DE ENSINO DE CIÊNCIA E TECNOLOGIA, 3. 2012, Ponta Grossa - PR. Anais. SINETC, 2012.

BRANCO, S. M. $O$ meio ambiente em debate. Ed. $3^{\text {a }}$ São Paulo: Moderna, 2004.

BRASIL. Secretaria de Educação Fundamental, Parâmetros Curriculares Nacionais: meio ambiente, saúde / Secretaria de Educação Fundamental v.9. Brasília: 1997.

BRASIL. Lei № 12.305, de 02 de agosto de 2010. Diário Oficial da República Federativa do Brasil, Brasília, DF, n. 147, 3 ago. 2010a. Seção 1. p. 3-7. Disponível em: <http://www.planalto.gov.br>. Acesso em: 12 dez. 2011.

BRASIL. Constituição (1988). Constituição da República Federativa do Brasil. 15를. São Paulo: Saraiva, 2013.

BRASIL. Ministério do Meio Ambiente e Ministério da Educação. Política nacional do meio ambiente, lei no 6.938, de 31 de agosto de 1981. 15ª Ed. São Paulo: Saraiva, 2013.

BRASIL. Presidência da República. Política nacional de resíduos sólidos, lei no 12.305, de 02 de agosto de 2010 e decreto no 7.404 de 23 de dezembro de 2010. 15ª Ed. São Paulo: Saraiva, 2013.

BRASIL. Ministério do Meio Ambiente. Política nacional de educação ambiental, lei no. 9.795 de 27 de abril de 1999. 15르 Ed. São Paulo: Saraiva, 2013.

BRASIL. Ministério da Educação e Desporto. Diretrizes e bases da educação nacional, lei no. 9.394 de 20 de dezembro de 1996, atualizada em 05 de outubro de 2011. 6 Ed. Brasília: Câmara dos Deputados, 2011.

BRASIL. Ministério da Educação, Secretaria de Educação Continuada, Alfabetização e Diversidade. Processo formador em educação ambiental à distância: modulo 4. Brasília: MEC, 2009.

BRASIL. Conselho Nacional de Educação. Resolução no $\mathbf{0 2}$ de $\mathbf{3 0}$ de janeiro de 2012. Brasília, DF: 2012. Disponível em: <http://portal.mec.gov.br>. Acesso em 03 ago. 2014.

CHUEIRI, M.F. Concepções sobre avaliação escolar. Estudos em Avaliação Educacional. São Paulo: v. 19, n. 39, jan./abr. 2008. 
DIEGUES, A.C.S. 0 mito moderno da natureza intocada. $3^{\text {a }}$ Ed. São Paulo: HUCITEC, 2001.

FORTUNATO, R.A.; NEFFA, E; MIRANDA, M. G. Potencialidades das visitas técnicas para o desenvolvimento de competências: o caso da horta comunitária do morro da coroa. Ambiente \& Educação. São Paulo. vol. 17 (1) p.29-45, 2012.

FREIRE, P. Educação e Mudança. Trad. Moacir Gadotti e Lílian Lopes Martin. 12를 ed. Rio de Janeiro: Paz e Terra, 1979.

FREIRE, P. Professora sim, tia não: cartas a quem ousa ensinar. São Paulo: Olho d'água, 1997.

FLORESTABILIDADE. Educação para o manejo florestal: livro do mediador. Rio de Janeiro: Fundação Roberto Marinho, 2012.

GUIMARÃES, M. A formação de educadores ambientais, $8^{a}$ Ed. Campinas SP: Papirus, 2012.

ILHAS DAS FLORES. Produção de Nora Goulart. Direção de Jorge Furtado. Porto Alegre: CASA DE CINEMA. 1989. Documentário (13'11”), son., color.

JANELA NATURAL. Produção de Elza Kawakami. Direção de Júlio César Carvalho. Rio de Janeiro: CANAL FUTURA. [200-?]. Documentário (7'03"), son., color.

LAYARGUES, P.P. Educação para gestão ambiental: a cidadania no enfrentamento político dos conflitos socioambientais. In. LOUREIRO, C. F. B; LAYRARGUES, P.P; CASTRO, R.S. (Org.). Sociedade e meio ambiente: a educação ambiental em debate. 7aㅡ Ed. São Paulo: Cortez, 2012.

LAYARGUES, P.P. O cinismo da reciclagem: o significado ideológico da reciclagem da lata de alumínio e suas implicações para a educação ambiental. In. LOUREIRO, F.; LAYARGUES, P.; CASTRO, R. (Org.) Educação ambiental: repensando o espaço da cidadania. São Paulo: Cortez, 2002, 179220.

LEONARD, A. A história das coisas: da natureza ao lixo, o acontece com tudo que consumimos. Trad. Heloisa Mourão. Rio de Janeiro: Zahar, 2011.

MARTINS, H.H.T.S. Metodologia qualitativa de pesquisa. Educação e Pesquisa. São Paulo: v.30, n.2, p. 287-298, maio/ago. 2004.

MENDES, R.; VAZ, A. Educação Ambiental no Ensino Formal: narrativas de professores sobre suas experiências e perspectivas. Educação em revista, Belo Horizonte, v.25, n.03, p. 395 - 411, dezembro. 2009.

NASCENTES PROTEGIDAS. Produção de Paraná (Estado) Secretaria de Estado do Meio Ambiente e Recursos Hídricos do Paraná. Curitiba - PR: SEMA. 2010. Documentário (11'57"), son., color. 
PEREIRA, C.A.S.; SILVA, L.C.S.; SALES, F.H.S. Análise do conforto acústico na biblioteca de uma escola pública. Holos. Natal: v. 4, p. 54-91, set. 2011.

PRIMACK, R.B.; RODRIGUES, E. Biologia da conservação. Londrina: Editora Planta, 2001.

QUADROS, F.S. Avaliação do ruído ambiental gerado por veículos de utilidade pública estudo de caso: caminhão de coleta de resíduos domiciliar. 144p. Dissertação (Mestrado em Engenharia Elétrica) - Programa de PósGraduação em Engenharia Mecânica, Universidade Federal do Paraná. Curitiba, 2004.

RICKLEFS, R. E. A economia da natureza. Trad. Pedro Paulo de Lima-e-Silva e Cecília Bueno. Rio de Janeiro: Guanabara Koogan, 2012.

RÖHRS, H. Maria Montessori. Trad. Danilo Di Manno de Almeida, Maria Leila Alves. Recife: Fundação Joaquim Nabuco, Editora Massangana, 2010.

REIGOTA, M. Meio ambiente e representação social. $2^{\underline{a}}$ ed. São Paulo: Cortez, 1997.

REIGOTA, M. O que é educação ambiental. São Paulo: Brasiliense, 1994.

TOLEDO, R.F; PELICIONI, M.C.F. Educação Ambiental em Unidades de Conservação. In: PHILIPPI JR., A.; PELICIONI, M.C.F. (ORG.). Educação ambiental e sustentabilidade. Barueri-SP: Manole, 2005.

VELLOSO, M.P. Os restos na história: percepções sobre resíduos. Ciência \& Saúde Coletiva. Rio de Janeiro: v.13 n.6, p. 1964, Nov./Dec. 2008.

VOLPATO, G L. Ciência: da filosofia à publicação. 6 a $^{\mathrm{a}}$ Ed. São Paulo: Acadêmica, 2013. 